\title{
Impact of Changes in National Healthcare Legislation and Financial Cuts by Insurance Companies on Use and Evaluation of Psycho-Oncological Care
}

\section{Adriaan Visser ${ }^{1 *}$, Anne Vennix ${ }^{2}$ and Margot Van Der Doef ${ }^{3}$}

${ }^{1}$ Research Centre Innovation in Care and Patient Education and Counselling, Rotterdam University of Applied Sciences, Rotterdam, The Netherlands

${ }^{2}$ Department of Psychology, De Vruchtenburg, Rotterdam, The Netherlands

${ }^{3}$ Faculty of Social Sciences, Psychology Institute Health, Medical Neuropsychology, Leiden University, Leiden, The Netherlands

\begin{abstract}
Objective: To study the impact of changes in national healthcare legislation and financial cuts by insurance companies on inflow of clients and their evaluation in psycho-oncological aftercare. These legislation changes and financial cuts did lead to a more complex in-take processes and less free-of-charge psycho-oncological care against higher costs. The psychosocial care concerns individual, cognitive behavioural, and art therapy.

Method: Two groups of clients were formed, based on financial policy cuts in 2012/2013 ( $N=334$ ) and 2014/2015 $(\mathrm{N}=360)$. Data was part of the annual evaluation by De Vruchtenburg (Psycho-oncological Centre, Rotterdam, the Netherlands). The questionnaire was filled at home after the therapy, returned postage free. Analyses applied ANOVA, Mann-Whitney and MANOVA tests.

Results: Results showed that due legislation changes and financial cuts fewer cancer clients visited the centre in 2014/2015 as compared to 2012/2013. In 2014/2015, clients were more frequently women, relatives and older patients, got therapy longer time after medical diagnoses, with more unknown prognosis. The measures led to delay in seeking psycho-oncological care. Clients in 2014/2015 evaluated more negatively their treatment compared to 2012/2013, regarding information about therapy, participation in choosing fitting therapy, and the counselling in general. Separately evaluation of the individual, cognitive behavioural and therapy gave identical results.

Conclusions: Psycho-oncological care became less accessible due to higher cost, as a result of national legislation policy and financial cuts in healthcare insurance. European studies should be promoted to increase insight into changing national financially thresholds for seeking psycho-oncological care.
\end{abstract}

Keywords: Health care policy; Health care insurances cuts; Inflow of clients; Evaluation; Support; Psycho-oncological therapy; Satisfaction

\section{Introduction}

Financial resources of patients influence the access to healthcare [1], although financial expenses for patients also depends on reimbursement by healthcare insurances and government legalisation for personal excess or deductible, with regulations for low-income groups, and other specific patient groups (children, elderly, chronically ill, refugees). Special financial regulations may also exist for cancer patients and their family members, because cancer as a medical illness and its treatment often include suffering of physical complaints, high anxiety, social isolation, spiritual and financial problems, and lower health related quality of life [2-7]. These problems did lead to offering several psycho-oncological facilities for cancer patients. Studies and reviews are reporting benefits of patient education, psychological counselling, support groups, home services, walk-in homes, and complementary care for cancer patients [7-14].

Comparative studies on health-economic profits of psychooncological interventions are not only lacking but also often difficult to compare [10,12,14-16]. Carlson and Bultz [17] pointed out positive medical offset of psycho-oncological interventions. Watson and Dunn [14] stressed lack of data on cost-effectiveness in psycho-oncology, although describing successful studies for breast cancer patients and community-based settings for highly-distressed patients [18]. Dieng [19] describe a protocol for economic evaluation of psycho-educational interventions for high-risk melanoma patients. Following this protocol, Jansen [20] stated in a review that psychosocial care is likely to be costeffective at different, potentially acceptable, and willingness-to-pay thresholds. Later Janssen et al. reported in their own study about costeffectiveness of supporting care for head and neck cancer patients [21].
The importance of insight how to implement health-economic studies in the psycho-oncological field is often stressed [7,8,11-23]. This did inspire us to study impact of changes in economic healthcare policy on use and evaluation of Dutch psycho-oncological care.

\section{Dutch psycho-oncological care}

The number of Dutch cancer survivors is increasing due to aging and improved treatment [22]; therefore, more cancer patients need to process a longer post-cancer period to find a new balance in their life [23]. The Dutch availability of psycho-oncological care is rather good and also very diverse e.g., national specialized centres, independent psychiatrists and psychologists, and in-hospital psychologists, psychiatrists, oncology nurses, and social workers may be consulted. About $12 \%$ of Dutch cancer patients make use of psycho-oncological care facilities [8], mainly aiming at improving their health-related quality of life (HRQOL). Dutch studies during and after psychooncological care, show that complaints of cancer patients and their relatives decreased, their HRQOL and wellbeing improved [2,7].

*Corresponding author: Adriaan Visser, Research Centre Innovation in Care and Patient Education and Counselling, Rotterdam University of Applied Sciences Rotterdam, The Netherlands, Tel: +31-10-4677857/31-6-22304087; E-mail adriaan.visser@planet.nl

Received December 04, 2018; Accepted December 27, 2018; Published December 29, 2018

Citation: Visser A, Vennix A, Doef MVD (2018) Impact of Changes in National Healthcare Legislation and Financial Cuts by Insurance Companies on Use and Evaluation of Psycho-Oncological Care. J Cancer Sci Ther 10: 392-398. doi: 10.4172/1948-5956.1000573

Copyright: (c) 2018 Visser A, et al. This is an open-access article distributed unde the terms of the Creative Commons Attribution License, which permits unrestricted use, distribution, and reproduction in any medium, provided the original author and source are credited. 
Citation: Visser A, Vennix A, Doef MVD (2018) Impact of Changes in National Healthcare Legislation and Financial Cuts by Insurance Companies on Use and Evaluation of Psycho-Oncological Care. J Cancer Sci Ther 10: 392-398. doi: 10.4172/1948-5956.1000573

Despite the proven effectiveness and high appreciation of psychooncological care by patients $[5,7,10]$, Dutch government and healthcare insurance companies have introduced major budget cuts over the last 10 years, in order to curtail the excessive rise of mental health costs [24,25]. Until 2011, psycho-oncological care was fully refunded, and use was practically unlimited and available for all cancer patients and their relatives. The most important changes after 2011 are presented in Table 1 . The strongest policy measure took place after 2013, leading to a more complex in-take process for providers and patients and less free-of-charge psycho-oncological therapy against higher costs for patients (Table 1).

\section{Research Questions}

The implications of changes in national legislation and healthcare insurance policies for psycho-oncological are studied on the inflow of clients, treatment evaluation, and HRQOL, comparing the years $2012 / 2013$ and 2014/2015 at an extramural centre for psycho-social care (De Vruchtenburg, Rotterdam, the Netherlands) [26-28]. The research questions were:

1. Did the inflow of the number of clients change between the years 2012/2013 and 2014/2015?

2. Did the composition of the inflow of clients between 2012/2013 and 2014/2015 change in respect of type of psycho-social therapies followed, gender, age, nationality, educational level, duration of former medical care, months since having cancer, and prognosis?

3. Did the evaluation of clients change concerning the received support, information supply and participation, the counselling provided by therapists, and the perceived treatment effectiveness, comparing the years 2012/2013 and 2014/2015?

4. Did the HRQOL change when comparing the years 2012/2013 and $2014 / 2015$ ?

These questions will be answered for clients who followed three most common therapies in total at the institute, as well as separately for patients taking part in individual, cognitive behavioural, and creative therapy. These therapies were applied to all type of cancer patients $[29,30]$.

\section{Methods}

\section{Setting and participants}

Data collection started in 2011, based on data from the annual questionnaire handled or sent to clients or relatives after finishing their therapy. Inclusion criterion was following the three therapies. Exclusion criteria were: receiving only one or two therapy sessions, too ill to participate in the study (view of the therapists), and not able to read or write Dutch language [31].

\section{Data collection}

Questionnaires were sent to patients or handed out by therapists after the therapy; clients could return the completed questionnaires by post, anonymously and free of charge. No reminders were sent to the clients for privacy reasons. The questionnaire has been developed, tested and used at the centre since 2004, and also used in other national studies $[5,31,32]$, containing questions on demographic and clinical variables, received treatment information, evaluation of the therapy, and the HRQOL. All measurements are based on answers by clients themselves. Also, the severity of the medical condition of the patients was not based on medical files. A study on prostate cancer patients show a strong comparison between subjective and medicinal file data on the illness condition of the patients $[33,34]$. Details about the measures are presented in Table 2.

\section{Statistical analysis}

Internal consistency of all the scales are tested by Cronbach's alpha coefficients. ANOVA tests were used to determine changes in characteristics of inflow of clients. ANOVA and Mann-Whitney tests were applied. The mean differences on scores evaluating the General Therapy Satisfaction, Information and Participation, Counselling Evaluation, Organisation of Care Evaluation, Perceived Effectiveness of Counselling and HRQOL between the years 2012/2013 and $2014 / 2015$ were tested by MANOVAs checking for the homogeneity of variance by significant differences in characteristics of the inflow of clients in these years. The assumption of homogeneity was tested when differences were found in the characteristics of client inflow. Finally, the data analysis was completed as described above for clients following the three types of therapy in 2012/2013 and 2014/2015 The p-value for significant differences was 0.05 (two side).

\section{Results}

The scales are presented in Table 3. The reliabilities (Crohnbach's alpha) of all the scales were higher than 0.80 [31].

\section{Number of clients}

The number of clients following therapy in 2012/2013 was in total 2202 and in 2014/2015 it were 1639 clients, a significant decrease. In $2012 / 2013 \mathrm{~N}=341$ clients filled in the questionnaire; in 2014/2015 $\mathrm{N}=376$ clients.

\begin{tabular}{|c|c|}
\hline Year & Legislation and health Insurance \\
\hline $2008-2011$ & $\begin{array}{l}\text { Use of primary GP and secondary/specialized care, both part of basis health insurance. } \\
\text { Secondary care: Fully reimbursed. } \\
\text { General personal deductible to be paid by the patients is } € 150 .\end{array}$ \\
\hline 2012-2013 & $\begin{array}{c}\text { Primary GP and secondary/specialized care are still both part of basis health insurance, but: } \\
\bullet \text { In primary care: Only five sessions, and patient contribution of } € 20 \text { per session. } \\
\text { - In secondary care: Short treatment, patient contribution of } € 100 \text { and longer treatment } € 200 \text {. } \\
\text { Adjustment disorder are no longer reimbursed. } \\
\text { General own risk is } € 220 \text {. }\end{array}$ \\
\hline 2014-2015 & $\begin{array}{l}\text { Primary and secondary became separated for basic and specialized care. } \\
\text { First to GP or the mental care assistant (POH-GGZ), who may refer to basic or specialized care } \\
\text { The GP or POH-GGZ: covered in basic health insurance, but: } \\
\text { - Basic and specialized care can only be reimbursed if a DSM-IV diagnosis is presented. } \\
\text { - Head of the therapy or an external psychiatrist needs to check the DSM-IV diagnosis } \\
\text { General personal deductible: } € 375 \text {. }\end{array}$ \\
\hline & legislation and health insurance policy in Dutch psycho-oncological care during 2008-2015. \\
\hline
\end{tabular}


Citation: Visser A, Vennix A, Doef MVD (2018) Impact of Changes in National Healthcare Legislation and Financial Cuts by Insurance Companies on Use and Evaluation of Psycho-Oncological Care. J Cancer Sci Ther 10: 392-398. doi: 10.4172/1948-5956.1000573

Demographic measures are: Gender, age, nationality, educational level of the participants. The clinical information consists of type of cancer, received medical treatment, the number of months since diagnosed with cancer, and the self-perceived prognosis. Questions on the therapeutic sessions followed: Which type of therapeutic treatment, the information received about the therapy, and duration of the therapy.

General satisfaction with received therapy is a scale of 1 to 10, indicating (1) as extreme negative and (10) as excellent. A score of 5 and lower indicates dissatisfaction.

Evaluation of therapy is measured on five scales: Information and Participation, Counseling Evaluation, Evaluation of Organisation of Care, Perceived Effectiveness of Counseling, and General Satisfaction on the therapy. A higher total score indicates a more negative evaluation of the provided care.

Scores on Information and Participation was based on six questions, e.g.: 'Did you receive enough information about the therapy and support opportunities provided, and 'Did you receive the opportunity to participate in the decision making about the followed therapy?'

Counseling Evaluation scale consists of seven questions with a four-point scale from '1=yes, of course' to '4=no, not at all'. E.g. 'Did you think the therapist was giving enough structure to the therapy?' 'Did you have enough trust in your therapist?'

Evaluation of Organisation of Care consists of three questions, four-point scale ranging from ' $1=y e s$, of course' to ' $4=$ no, not at all'. E.g. 'Was the treatment plan carried out as you wanted?'

Perceived Effectiveness scale consists of 24 statements, four answer options (1=yes, 2=no, 3=partially, and 4=does not apply to me). E.g. 'Due to the treatment I gained more insight in how I cope with emotions and problems', 'Due to the treatment I learned to cope with the stress and emotions caused by the cancer'; 'Due to the treatment I found more rest and balance in my life'.

HRQOL is developed and applied in earlier studies [36] consists of two questions: 'How would you rate your overall health during the past week?' and 'How would you rate your quality of life during the past week?', using a seven-point scale (1=really bad to 7=excellent). A higher score indicates a higher HRQOL.

Table 2: The applied measurements in the study [31]

\begin{tabular}{|c|c|c|c|c|c|}
\hline \multicolumn{2}{|c|}{ Measurement } & 2012/2013 & $2014 / 2015$ & $F(d f 1, d f 2)$ & $p$-value \\
\hline \multirow{3}{*}{ Gender } & Women & $238(71.3 \%)$ & $283(77.1 \%)$ & \multirow{3}{*}{ ** } & \multirow{3}{*}{$0.032^{*}$} \\
\hline & \multirow{2}{*}{ Men } & $96(28.7 \%)$ & $77(21.4 \%)$ & & \\
\hline & & $\mathrm{N}_{\text {total }}: 334$ & $\mathrm{~N}_{\text {total }}: 360$ & & \\
\hline Age & & $\begin{array}{c}53.0( \pm 13.2) \\
\mathrm{N}_{\text {total }}: 334\end{array}$ & $\begin{array}{c}55.0( \pm 12.5) \\
\mathrm{N}_{\text {total }}: 361\end{array}$ & $4.277(1,693)$ & $0.039^{*}$ \\
\hline \multirow{3}{*}{ Nationality } & Dutch & $324(98.8 \%)$ & $350(97.2 \%)$ & \multirow{3}{*}{$0.308(1,693)$} & \multirow{3}{*}{0.579} \\
\hline & \multirow[t]{2}{*}{ Other } & $4(1.2 \%)$ & $10(2.8 \%)$ & & \\
\hline & & $\mathrm{N}_{\text {total }}: 328$ & $\mathrm{~N}_{\text {total }}: 360$ & & \\
\hline \multirow{6}{*}{ Educational level } & Primary school & $16(4.9 \%)$ & $10(2.8 \%)$ & \multirow{6}{*}{$0.028(1,686)$} & \multirow{6}{*}{0.867} \\
\hline & Lower education & $36(11.0 \%)$ & $39(10.9 \%)$ & & \\
\hline & High school & $129(39.6 \%)$ & $148(41.2 \%)$ & & \\
\hline & Applied University & $93(28.5 \%)$ & $118(32.9 \%)$ & & \\
\hline & \multirow{2}{*}{ University } & $52(16.0 \%)$ & $44(12.3 \%)$ & & \\
\hline & & $\mathrm{N}_{\text {total }}: 326$ & $\mathrm{~N}_{\text {total }}: 359$ & & \\
\hline Mean months since visiting the & & $4.5( \pm 1.7)$ & $4.5( \pm 1.7)$ & \multirow{2}{*}{$0.187(1,684)$} & \multirow{2}{*}{0.666} \\
\hline centre & & $\mathrm{N}_{\text {total }}: 328$ & $\mathrm{~N}_{\text {total }}: 358$ & & \\
\hline \multirow{3}{*}{ Status } & Patient & $290(85 \%)$ & $273(75.6 \%)$ & \multirow{3}{*}{ ** } & \multirow{3}{*}{$0.002^{*}$} \\
\hline & \multirow{2}{*}{ Partner } & $51(15.0 \%)$ & $88(24.4 \%)$ & & \\
\hline & & $\mathrm{N}_{\text {total }}: 341$ & $\mathrm{~N}_{\text {total }}: 361$ & & \\
\hline $\begin{array}{l}\text { Months having cancer } \\
\text { (subjective data) }\end{array}$ & & $\begin{array}{c}14.6( \pm 19.9) \\
\mathrm{N}_{\text {total }}: 210\end{array}$ & $\begin{array}{c}33.6( \pm 45.8) \\
\mathrm{N}_{\text {total }}: 258\end{array}$ & ** & $<0.001^{*}$ \\
\hline \multirow{6}{*}{ Prognosis (subjective data) } & Unknown & $52(22.0 \%)$ & $120(45.3 \%)$ & \multirow{6}{*}{ ** } & \multirow{6}{*}{$<0.001^{*}$} \\
\hline & Recovered & $68(28.8 \%)$ & $69(26.0 \%)$ & & \\
\hline & Good chance for recovery & $72(30.5 \%)$ & $63(23.8 \%)$ & & \\
\hline & Life-prolonging treatment & $36(15.3 \%)$ & $11(4.2 \%)$ & & \\
\hline & \multirow{2}{*}{ No treatment possible } & $8(3.4 \%)$ & $2(0.8 \%)$ & & \\
\hline & & $\mathrm{N}_{\text {total }}: 236$ & $\mathrm{~N}_{\text {total }}: 265$ & & \\
\hline \multirow{10}{*}{ Therapies } & Individual & $288(91.1 \%)$ & $296(81.8 \%)$ & \multirow{10}{*}{$\begin{array}{c}* * \\
* * \\
* * \\
0.063(1,566) \\
0.189(1,561) \\
0.732(1,557) \\
\text { ** } \\
\text { ** } \\
\text { ** } \\
\text { ** }\end{array}$} & \multirow{10}{*}{$\begin{array}{c}<0.001^{*} 0.046^{*} \\
0.153 \\
0.802 \\
0.664 \\
0.392 \\
0.153 \\
0.628 \\
0.369 \\
0.194\end{array}$} \\
\hline & Haptotherapy & $37(17.1 \%)$ & $21(5.8 \%)$ & & \\
\hline & Recovery \& Balance & $23(11.2 \%)$ & $22(6.1 \%)$ & & \\
\hline & Creative therapy & $29(13.9 \%)$ & $53(14.6 \%)$ & & \\
\hline & Partner meetings & $5(2.5 \%)$ & $7(1.9 \%)$ & & \\
\hline & Training CBT & $56(24.7 \%)$ & $61(16.9 \%)$ & & \\
\hline & Life after cancer group & $8(4.0 \%)$ & $6(1.7 \%)$ & & \\
\hline & Cancer in perspective & $4(2.0 \%)$ & $4(1.1 \%)$ & & \\
\hline & Dealing with loss & $5(2.5 \%)$ & $4(1.1 \%)$ & & \\
\hline & Therapy for children & $6(3.0 \%)$ & $4(1.1 \%)$ & & \\
\hline \multicolumn{5}{|l|}{ 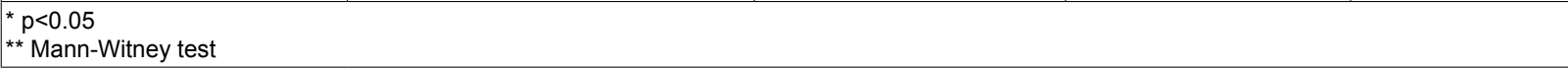 } & \\
\hline
\end{tabular}

Table 3: Descriptive of samples and differences in client inflow in 2012/2013 and 2014/2015 
Citation: Visser A, Vennix A, Doef MVD (2018) Impact of Changes in National Healthcare Legislation and Financial Cuts by Insurance Companies on Use and Evaluation of Psycho-Oncological Care. J Cancer Sci Ther 10: 392-398. doi: 10.4172/1948-5956.1000573

\begin{tabular}{|c|c|c|c|c|c|}
\hline Evaluation measures (1) & $\begin{array}{c}2012 / 2013 \\
M( \pm S D)\end{array}$ & $\begin{array}{c}2014 / 2015 \\
M( \pm \text { SD) }\end{array}$ & $F(d f 1, d f 2)$ & $p$-value & Effect size \\
\hline Information and participation & $8.2( \pm 3.0)$ & $15.8( \pm 7.2)$ & $33.31(1,173)$ & $<0.001^{*}$ & 0.161 \\
\hline Counselling evaluation & $8.0( \pm 2.3)$ & $19.0( \pm 9.9)$ & $22,75(1,173)$ & $<0.001^{*}$ & 0.116 \\
\hline Care organisation evaluation & $4.0( \pm 1.8)$ & $4.0( \pm 1.7)$ & $1.168(1,173)$ & 0.281 & 0.007 \\
\hline Perceived treatment effectiveness & $50.4( \pm 14.2)$ & $53.0( \pm 15.1)$ & $3.10(1,173)$ & 0.080 & 0.018 \\
\hline HRQOL & $11.1( \pm 2.0)$ & $11.2( \pm 1.9)$ & $0.475(1,173)$ & 0.492 & 0.003 \\
\hline General therapy satisfaction & $\begin{array}{c}8.2( \pm 1.2) \\
N=334\end{array}$ & $\begin{array}{c}8.2( \pm 1.2) \\
\mathrm{N}=363\end{array}$ & $0.063(1,684)$ & 0.801 & -- \\
\hline \multicolumn{4}{|c|}{ * $\alpha=0.05 ;(1)$ a higher score indicates a lower evaluation } & & \\
\hline
\end{tabular}

Table 4: Means and standard deviations of the measurement scales, HRQOL and general therapy evaluation, differences between $2012 / 2013$ and 20142015 controlling for differences in client inflow [1].

\section{Inflow of clients}

It shows that the composition of the inflow of clients in 2014/2015 was different as compared to clients in 2012/2013 (Table 1). In 2014/2015 more women and partners and partners visited the centre than in $2012 / 2013$, and also the mean age of the clients was higher in 2014/2015. Furthermore, more clients in 2014/2015 had been diagnosed with cancer a longer time ago and received an unknown prognosis more often. The clients in 2014/2015 followed less often individual therapy than the clients in 2012/2013 (Table 3).

\section{Therapy evaluation}

Controlled for differences found in the inflow characteristics (Table 4), the clients from 2014/2015 were less satisfied as compared to clients from 2012/2013 about the Information and Participation $\left(\mathrm{F}(1,173)=33.31, p<0.001, \eta^{2}=0.161\right)$, especially about the therapy options, the therapy content, the expected therapy outcome, and their participation in the decision about which therapy to follow (not shown). In 2014/2015 the clients were also less satisfied about the Counselling $\left(F(1,173)=22.75, p<0.001, \eta^{2}=0.116\right)$ e.g., the expertise, commitment, confidentiality, respectfulness, interest of the therapists, and the level of insight and structure provided by the therapists. The evaluation of the Perceived Effectiveness shows no difference between both year groups, although the clients in 2014/2015 are marginally less satisfied $(p=.08)$. The Evaluation of the Organisation of the Counselling and the general evaluation of the therapy did not show differences between both year groups (Table 4 ).

\section{The HRQOL}

The scores on the overall HRQOL did not differ between 2012/2013 and 2014/2015 (Table 4).

\section{Effects for specific therapies}

The inflow of clients and their treatment evaluation for the years 2012/2013 and 2014/2015 were also compared separately for individual therapy, cognitive behavioural therapy, and art therapy. The results do not differ from the analyses on all therapies together [31].

\section{Discussion and Conclusion}

The goal was to study the impact of the national health care legislation and financial restrictions by healthcare insurance companies on inflow of clients, their treatment evaluation, and HRQOL for clients receiving psycho-oncological care in 2012/2013 and 2014/2015. It is not possible to compare the results by studies from other Dutch psycho-social care institutes, because no other institutes collect such data. Also, the comparison of results with studies in other countries is restricted because those types of changes and policy measures happened differently at different moments in time in other European countries [16]. Further, it is rather impossible to compare the factors that influence the price patients have to pay for psycho-oncological care, even within Europe [15]. Finally, the cost and its reimbursement for psycho-oncological care in some European countries may be lower than in the Netherlands because this care may be part of the (hospital) care (e.g., UK, Belgium), often offered in cooperation with hospitals (Germany, France, Scandinavia) or may be higher for extramural facilities like in the Netherlands, but it at the same time the costs may be lower due to a higher reimbursement procedures [16]. Our study shows several influences of legislation and health insurance cuts on inflow of clients and their treatment evaluation. The results may have meaning for this type of care changes in other (European) countries.

\section{Inflow of clients}

The inflow of the number of clients decreased significantly between the years 2012/2013 and 2014/2015. An initial explanation is that the GP practices changed due to the introduction of the Mental Health Care Assistance (POH-GGZ) in the primary care system (Table 1). This did lead to a decrease of the number of clients referred to specialized psycho-oncological care institutes. A second factor as presented in Table 1 is the required need of a DSM-IV diagnosis for more severe complaints, which caused that clients and relatives with less severe problems were not referred to psycho-oncological care. Both factors explain that it became harder to receive specialized psychological care in 2014/2015. This may explain the decrease of the number of clients receiving therapy in $2012 / 2013(\mathrm{~N}=2202)$ compared to 1639 clients in 2014/2015. This trend may be in fact also true for other countries, because the access to psycho-oncological services is often restricted $[7,8,14]$

\section{Composition of the in-flow of clients}

There were multiple changes found in characteristics of the inflow of clients. First, more women received therapy in 2014/2015. An explanation is that female cancer patients are twice as likely to experience anxiety and depression than male cancer patients [4]. The consequence is that more women could receive therapy in 2014/2015, fulfilling the strict requirement of an available DSM-IV diagnosis to reimburse the received therapy $[24,25]$.

The second difference was the higher age of clients in 2014/2015. This contradicts the study of Dinkel [32], that the anxiety levels of cancer patients are lower between the age of 50 and 70 . However, the increase in age was rather small (only 2 years on the average in both samples), so age cannot be seen as a critical difference between the two studied groups of years.

Further, clients in 2014/2015 were more often relatives of cancer patients compared to the clients in 2012-2013. This was neither 
intended nor expected, since the changes in healthcare insurance and legislation made it more difficult for relatives to receive psychooncological care, due to the removal of general disorder complaints for receiving covered psycho-oncological care as well as the requirement of a DSM-IV diagnosis to get the care reimbursed [25]. An explanation is that due to a delay in seeking therapy, the psychological complaints of the relatives became more severe, leading to the possibility of receiving finally the required DSM-IV diagnosis, which opened their legal way to therapy. This explanation is supported by the study of Alacacioglu [4], finding that $29 \%$ of the relatives of cancer patients is depressed.

Finally, clients in 2014/2015 had been diagnosed with cancer relatively earlier, as compared to clients in 2012/2013. This might indicate a delay in receiving the proper psycho-oncological care. The difference in time passed since receiving the cancer diagnosis might also have been caused by the increase in the personal deductible costs and the change in the care system, which designated the mental healthcare assistance as a primary care in 2014 [23], making it more difficult to receive the basic or specialized psycho-oncological support quickly. According to Visser [35] and Schrader [36], clients like to receive the support of the mental health care assistant because a referral to the basic or specialized care was not covered in their healthcare insurance anymore. Also, for the health insurance companies is this favourable effect, because care given by mental healthcare assistances (POH-GGZ) is more profitable [36]. So, the increase in the duration of having cancer can be explained by the fact that people first visit the mental health care assistant, which increases the time before more specialized care is looked at. A factor that might also have influenced the increase in months having cancer, can be the importance of having a DSM-IV diagnosis. Since 2014 clients need a psychiatric diagnosis based on the DSM-IV in order to receive care in the basic or specialized mental health care [36]. This implied that many DSM-IV diagnoses such as adjustment disorder, relationship problems, sexual disorders and work disorders, were no longer covered by health care insurances [25]. The psychological problems became more severe before patients could be referred to the basic or specialized mental health care.

\section{Therapy evaluation}

Clients receiving therapy in 2014/2015 evaluated the therapy more negatively on Information and Participation and Counselling than clients in 2012/2013. However, the Perceived Treatment Effectiveness and the overall Therapy Satisfaction did not decrease. Only clients following individual therapy were less satisfied with the information given about the therapy, their participation in this process and the counselling, and they are also less positive about the perceived treatment effectiveness.

An explanation that clients were less positive about the information given about the therapy participation and counselling in 2014/2015, but did not evaluate the therapy as less effective, might be that clients were unfamiliar with how the new care system worked. Clients might not know that the DSM-IV diagnosis given by the psychologists need to be checked by the head of the therapy or by an external psychiatrist, resulting for them having to explain their problems at least twice. Clients may therefore perceive that psychologists do not assess their psychological complaints adequately, which influences negatively the evaluation of the Information, Participation and Counselling. However, the actual received treatment was still the same and thus evaluated positively. This may have not been perceived in the individual therapy.

There was also a greater diversification found in the scores given by clients caused by the fact in 2014/2015 different groups of clients visited the centre as indicated before. Different groups of clients were using the therapy, making the difference in evaluations more plausible.

\section{HRQOL}

Due to the higher threshold to psycho-oncological care, the HRQOL scores would be lower in 2014/2015 because the clients with more severe psychological complaints (and thereby a lower HRQOL) could only receive treatment by the GP and the mental care assistant and could not be referred to specialized psycho-oncological care institute $[35,36]$. However, no differences in the HRQOL scores given by clients in 2012/2013 and 2014/2015 were found, although the HRQOL is a sensitive measure [37]. This means that the severity of the psychological problems of the group of patients has not changed, indicating that the changes in health care policy may did not affect the severity of psychological problems of the clients.

\section{Study Limitations and Strengths}

- A first restriction is the design, because the study is a local crosssectional non-longitudinal evaluation of nation-wide changes in the Dutch healthcare policy. It is a post-design field study that could not be performed as RCT due to the multiple changes over time. That restricts strongly causal conclusions. The study is based on existing data files; this implies restrictions on the available measures. It is also important to stress the rather large drop-out rate of the number of clients that followed a therapy as well as the lower number of clients that completed the questionnaires, and the applied exclusion criteria [31]. However, the results of seven years of the studies at the same institute did not show a drop-out bias in the data [32]. The study is exclusively based on data within Dutch health care with its own unique characteristics and availability of specific psycho-oncological care. This restricts the generalisation of conclusions about other healthcare systems in other countries. There are no comparable health-economic or psycho-oncological service data available from other institutes or European countries [14-16].

- A second limitation is that the assumption of homogeneity of covariance matrices was violated, decreasing the impact of the study. However, because of the equal cell sizes and a relatively high number of participants, the results could still be interpreted carefully [38].

- A third limitation is that data is based only on self-report of clients. Self-report data has the disadvantage of being more erroneous because of the measurement error and the possibility of conscious bias [39]. This may mean that the clients who filled in the questionnaire could be more positive or negative than in reality due to e.g., a social desirability tendency. Other studies show however that such biases are small $[31,32]$.

- Fourth, having information about the severity of the psychological problems would also have made the study much stronger. If those data had been available, the effect of removing DSM-IV diagnosis from the covered mental health care could have been studied better, because changes in the severity of the psychological problems could have been shown.

- The final limitation of the present study is the single time measure of the HRQOL. The changes in the objective and perceived effectiveness of the therapy could not been studied.

However, there are also strength points in the study. A first strength is the number of clients. In both groups of years, the number 
Citation: Visser A, Vennix A, Doef MVD (2018) Impact of Changes in National Healthcare Legislation and Financial Cuts by Insurance Companies on Use and Evaluation of Psycho-Oncological Care. J Cancer Sci Ther 10: 392-398. doi: 10.4172/1948-5956.1000573

of clients is rather high, increasing the ability to draw generalizations from the study. A second strength is using the significant differences in the inflow of clients between the years 2012/2013 and 2014/2015 as covariates by examining the differences in therapy evaluation between the years 2012/2013 and 2014/2015.

\section{Clinical Implications}

Changes in national mental health organization, its finances and the policy of healthcare insurances had negative implications for the psycho-oncological care. This is a lesson for other European countries which are developing and changing the finances of psycho-oncological care [14-16]. These changes should be communicated clearly and comprehensibly to therapists and their clients, which would cause less social unrest as happened now [40]. When complex health care changes are not clearly communicated, this may have negative consequences for the inflow of clients who need the counselling as well as for the use and evaluation of the psycho-oncology care facilities. Drastic changes in the healthcare facilities may also influence the relationship between therapists and clients, which has unintentional consequences on the effects of counselling, and as such also for the quality of life of cancer patients. The implications mentioned, require more psychooncological evaluation studies. A Dutch pilot study about the effects of the psychological treatment of minor adjustment problems started in 2018 , which could be officially and legally introduced again adjustment problems in the care facilities [41]. In a broader perspective, it is important to study more the effects of financial and healthcare insurances measures of European countries with the comparing healthcare and psycho-oncological facilities.

\section{Acknowledgments}

Thanks to participating clients, therapists, the Vruchtenburg, and Margo Remie health psychologist, working at this centre during the study. The English text was corrected by Rosalie Steinmann.

\section{Conflict of Interest}

There is no conflict of interest.

\section{Informed consent}

The informed consent by the Vruchtenburg (Psycho-oncological Centre Rotterdam, the Netherlands) is based on the national research programme for studying effects of therapy. The text in the letter was: "Due to the realization of an optimal treatment and to improve the quality of the care, we will ask you to fill in a questionnaire. The anonymous answers will also be used for comparative scientific research. Fill in below: "Place, Date, Signature". The form was filled in after the in-take being a part of the patient dossier, including the completed questionnaire.

\section{Ethical Approval}

The studies at the Vruchtenburg have been approved since 2004 by the Board of Trustees and the Patients' Policy Trust Group. There is no registration of an ethics approval committee for the study, but there was a statement in the introduction letters in all questionnaires: "There is a national legal requirement to ask the clients about their opinion on the received treatment" (quote, date on the signed letter).

\section{References}

1. Andersen RM (1995) Revisiting the behavioral model and access to medical care: Does it matter?. J Health Soc Behav 36: 1-10.

2. Hagedoorn M, Kreicbergs U, Appel C (2011) Coping with cancer: The perspective of patients' relatives. Acta Oncol 50: 205-211.

3. Girgis A, Lambert S, Johnson C, Waller A, Currow D (2013) Physical, psychosocial, relationship and economic burden of caring for people with cancer: A review. J Oncol Pract 9: 197-202.

4. Alacacioglu A, Tarhan O, Alacacioglu I, Dirican A, Yilmaz U (2013) Depression and anxiety in cancer patients and their relatives. J BUON 18: 767-774.

5. Garssen B, Van Der Lee M, Van Der Pol A, Ranchor A, Sanderman R, et al. (2011) Psycho-oncology helps; evaluation of specialized Dutch psychooncology care in the Netherlands [Dutch Psycho-oncology helps: Evaluation of specialized psycho-oncological care in the Netherlands]. Institutions PsychoSocial Oncology (IPSO), Utrecht.

6. Linden W, Vodermaier A, Mackenzie R, Greig D (2012) Anxiety and depression after cancer diagnosis: Prevalence rates by cancer type, gender, and age. $J$ Affect Disord 141: 343-351.

7. Haes JCJM, Van-Weezel LMG, Sanderman R, Wiel HBM (2001) Psychological patient care in cancer [Dutch Psychological patient care in oncology]. Manual for professionals. Axles: Van Gorcum.

8. 8. http://www.ipso.nl/over-ipso/zorg-en-ondersteuning-bij-kanker.

9. Tralongo P, Ferrau F, Borselino N,Verderama F, Canus M, et al. (2011) Cancer patient-centered home care: A new model for health care in oncology. Ther Clin Risk Manag 7: 387-392.

10. Stenberg U, Vagan A, Flink M, Lynggaard V, Fredriksen K, et al. (2018) Health economic evaluations of patient education interventions: A scoping review of the literature. Patient Educ Couns 101: 1006-1035

11. Dieng M, Cust AE, Kasparian NA, Mann GJ, Morton RL (2016) Economic evaluation of psychosocial interventions in cancer: A systematic review. Psycho-oncology 25: 1380-1392.

12. Ussher JM, Perz J, Hawkins Y, Brack M (2009) Evaluating the efficacy of psycho-social interventions for informal carers of cancer patients: A systematic review of the research literature. Health Psych Rev 3: 85-107.

13. Appleton L, Pool H, Wall C (2018) Being in safe hands: Patients' perceptions of how cancer services my support psychological well-being. J Adv Nurs 1: 1-13.

14. Watson M, Dunn J (2016) The multidisciplinary art and science of cancer care: Integrating psycho-oncology. Fut Oncol 12: 2775-2778.

15. Grassi L, Watson M (2012) IPOS Federation of Psycho-Oncology Societies' co-authors: Psychosocial care in cancer: An overview of Psychosocia programmes and national cancer plans of countries within the International Federation of Psycho-Oncology Societies. Psycho-Oncology 21: 1027-1033.

16. Duijts S, Hillen M (2015) Psycho-oncology Worldwide [Dutch: Psycho-oncology worldwide]. Theme number. Int J Psy Oncol 23: 4-5.

17. Carlson LE, Bultz BD (2004) Efficacy and medical cost offset of psychosocial interventions in cancer care: Making the case for economic analyses. PsychoOncology 13: 837-849.

18. Tyler T (2013) Bridging the psychosocial and financial. Oncology 24: 40-49.

19. Dieng M, Cust AE, Kasparian NA, Butow P, Costa DS, et al. (2016) Protocol fo a within-trail economic evaluation of a psychoeducational intervention tailored to people at high risk of developing a second or subsequent melanoma. BMJ Open 6: e012153.

20. Jansen F, Van Zwieten V, Coupé VM, Leemans CR, Verdonck-de Leeuw IM (2016) A review on cost-effectiveness and cost-utility of psychosocial care in cancer patients. Asia Pac J Oncol Nurs 3: 125-136.

21. Jansen $F$ (2018) Supportive care in head and neck cancer patients: Patientreported needs and costs. Clinical Psychology 2: 1.

22. https://www.volksgezondheidenzorg. info/onderwerp/kanker.

23. Nagtegaal T, Kooij A, Lammens C (2012) Millions in spending cuts in menta healthcare care for cancer patients [Dutch: Millions cutbacks in mental health care are taking care of cancer patients]. Psychosocial Oncology 20: 14-15.

24. Ministry of Health, Welfare and Sport (2012) Effects of the personal excess / deductible. Retrieved from: https://zoek.officielebekendmakingen.nl/blg 186533.pdf.

25. http://www.nvpo.nl/wp-content/uploads/2015/10/psychosociale-zorg-bijsomatische-aandoeningen.pdf.

26. Vruchtenburg (2015) Mission and Vision [Dutch: Mission and Vision]. Retrieved from [http://www.devruchtenburg.nl/visie-en-missie] Accessed on: December 27, 2015.

27. Vruchtenburg (2015) Psychological care in the Vruchtenburg [Dutch Psychological Care at De Vruchtenburg]. Retrieved from [http://www. devruchtenburg.nl/begeleiding-bij-de-vruchtenburg] Accessed on: December 27, 2015.

28. Vruchtenburg (2015) For referals [English: L for Referrers. Retrieved from 
Citation: Visser A, Vennix A, Doef MVD (2018) Impact of Changes in National Healthcare Legislation and Financial Cuts by Insurance Companies on Use and Evaluation of Psycho-Oncological Care. J Cancer Sci Ther 10: 392-398. doi: 10.4172/1948-5956.1000573

[http://www.devruchtenburg.nl/voor-zorgverleners/] Accessed on: December $27,2015$.

29. Daly MC, Duncan GJ, McDonough P, Williams DR (2002) Optimal indicators of socioeconomic status for health research. Am J Public Health 92: 1151-1157.

30. Cutler DM, Lleras-Muney A (2006) Education and health: Evaluating theories and evidence (No. w12352). National Bureau of Economic Research, Voorburg.

31. Vennix A, Visser A, Van der Doef M (2016) Effects of changes in health insurance and legislation on the inflow of clients and the treatment evaluation for clients receiving psycho-oncological care at the Vruchtenburg, Pro-health. org, Rotterdam, Institute of Health Psychology, Leiden University, Leiden, De Vruchtenburg, Rotterdam, The Netherlands.

32. Visser A, Wildenbeest M (2012) Psycho-social support in the Vruchtenburg. Pallium 1: 8-10.

33. Voerman B (2016) Psychosocial problems and interventions in prostate cancer Patients. University of Groningen, The Netherlands.

34. Dinkel A, Kremsreiter K, Marten-Mittag B, Lahmann C (2014) Comorbidity of fear of progression and anxiety disorders in cancer patients. Gen Hosp Psychiatry 36: 613-619.
35. Visser S (2015) General Mental Health Care, Generalist basic GGZ. Psychopractice 7: 1-1.

36. Schrader W (2015) Burden and risks of referrals to mental health care. GP and Science 58: 141-141.

37. UMC Utrecht (2015) Vision psychosocial oncological for personalized care Avilable at: https://www.umcutrecht.nl/nl/Ziekenhuis/Afdelingen/Cancer enter /Patientenparticipatie/Visie-PSOZ-op-maat-2015.aspx, Accessed on: December 27, 2015

38. Cella D, Stone AA (2015) Health-related quality of life measurement in oncology: Advances and opportunities. Am Psychol 70: 175-185.

39. Schoeller DA (1995) Limitations in the assessment of dietary energy intake by self-report. Metabolism 44: 18-22.

40. NOS (2016) Coalition demands more attention to psychiatric problems in severe illnesses (Dutch; Coalition wants more attention for psychological problems in serious illness). [http://nos.nl/artikel/2111399-coalitie-wil- more-attention-for psychological problems-at-serious-illness.html] Accessed on: June 25, 2016

41. News Letter NVPO (2018) Pilot study adjustment problems [Dutch; Aanpassingsstoornis]. 